\title{
ARTICLES
}

\section{AN OBSERVATORY STUDY TO ASSESS THE QUALITY OF CARE PROVIDED BY TRAINED MIDWIVES IN FIRST STAGE, SECOND STAGE AND THIRD STAGE OF LABOUR IN SELECTED HOSPITALS OF INDORE IN THE YEAR 2016 - 2017}

\author{
Mrs. Sneha M. George* I Dr. Usha Ukande** \\ * Researcher, Tutor, L.N. Nursing College, Bhopal, M.P, India. \\ ** Guide \& Principal, Choithram College of Nursing, Indore, M.P, India. \\ DOI: http://doi.org/10.47211/idcij.2020.v07i03.015 \\ Received $15^{\text {th }}$ June 2020, Accepted 27 $7^{\text {th }}$ June 2020, Available online $10^{\text {th }}$ July 2020.
}

\section{ABSTRACT}

An observatory study was undertaken to assess the quality of care provided by trained midwives in first stage, second stage and third stage of labour at selected hospitals of Indore. The population consisted of trained midwives working in maternity unit with minimum 6 months' experience. A quantitative research design approach was adopted. A sample size of 100 was taken in which 50 were from government and 50 from private hospitals, selected by using purposive sampling. Data were collected by using self-structured observatory checklist prepared by WHO and ICM competencies. Results revealed that among the selected 58 competencies from WHO and ICM, 10 competencies are followed in a better way by TM of government hospital as compared to TM of private hospital. Hence there is a vast difference between quality of care in both government and private hospitals. The quality of care of private hospital is much better as compared to government hospitals.

Key Words: Trained Midwives, Practice, WHO Competencies, ICM Competencies.

\section{ABOUT AUTHORS:}

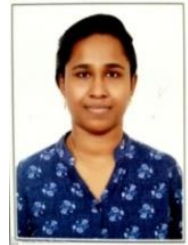

Author Mrs. Sneha M George, is a tutor at L N Nursing College at Bhopal in the state of Madhya Pradesh, India. She has attended various national and international conferences and workshops.

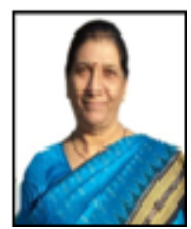

Author Dr. Usha Ukande is Principal of Choithram College of Nursing and National President of NRSI and Hon. Secretary of Midwives, M.P Chapter. 


\section{INTRODUCTION}

\section{"Better know nothing than half know many things"}

- Friedrich Nietzsche

Pregnancy is a seemingly a long journey that is best travelled with support. Labour is almost an overwhelming experience because it involves sensations and emotions at such an intense level. Women need supportive persons with them to cope with their experience of labour. Pregnancy is a unique, exciting and often joyous time in a woman's life, as it highlights the woman's amazing creative and nurturing powers while providing a bridge to the future.

Normal labour occurs at term and is spontaneous in onset with the foetus presenting by vertex. The process is completed within 18 hours and no complications arise. The physiological, psychological and emotional experience of labour affects every woman differently. The midwife who is with the women during $2^{\text {nd }}$ stage has a great responsibility in observing and monitoring the uterine contractions, descent of the presenting part, as well as monitoring foetal and maternal conditions. The midwives care of the mother would be based on an understanding of the normal physiological process at work. Her action can reduce the very real risk of haemorrhage, infection, retained placenta and shock, any of which may increase maternal mortality and morbidity

Nurses working in perinatal settings are in a unique position to screen, monitor, and provide care to patients who are affected by complications during pregnancy. It is essential for nurses to be familiar with these complications, as well as the maternal and foetal implications, medical treatment, and nursing care necessary to address these problems.

\section{PROBLEM STATEMENT}

"An observatory study to assess the quality of care provided by trained midwives in first stage, second stage and third stage of labour in selected hospitals of Indore in the year 2016 - 2017"

\section{OBJECTIVES OF THE STUDY}

- To evaluate the quality of care in stages of labour provided by trained midwives in the first stage, second stage and the third stage.

- To compare the quality of care provided by trained midwives in stages of labour (first stage, second stage and third stage) in government and private hospital settings.

\section{RESEARCH METHODOLOGY -}

Research Approach: Quantitative approach

Research design: An observatory study design

Setting of the study: The study was conducted in both government and private hospitals.

Population: In the present study, the target population was trained midwives working in labour ward.

Sample and Sampling Technique -

Sampling Technique: Purposive sampling technique was used for the present study, to select the patients,

Sample Size: Sample size consisted of 100 samples (50 from private and 50 from government hospital) that fulfilled the inclusion criteria.

Settings: This study was conducted in Govind Vallabh Pant District Hospital and Choithram Hospital \& Research Centre

Tools: The tools used in the study are -

Section A - Questionnaire of Socio-demographic variables.

Section B - Checklist to assess the quality of care in different stages of labour: -

- Supportive care during labour

- Care on admission.

- Care at first stage of labour.

- Care at second stage of labour.

- Care of the new born.

- Care at third stage of labour

\section{FINDINGS}

Data presented in table illustrates that almost $100 \%$ (50) of supportive care provided in private hospital was according to WHO \& ICM competencies, whereas only $80 \%$ (40) of supportive care provided in government hospital was according to WHO \& ICM competencies and $20 \%(10)$ of care was not according to it. In both 
private and government hospitals, almost $100 \%$ (50) of care on admission was according to WHO \& ICM competencies. $90 \%$ (45) of care at first stage was according to competencies and $10 \%(5)$ of care was not accordingly practiced in private hospital whereas more than half $60 \%(30)$ of care at first stage of labour was according to WHO \& ICM competencies and $40 \%$ (20) of care was not according to it in government hospital. In care at second stage of labour, $96 \%$ (48) of care provided was according to competencies and $4 \%$ (2) of care was not accordingly provided in private hospital, whereas, in government hospital $90 \%$ (45) of care was according to WHO \& ICM competencies and 10\% (5) of care was not according to it. The care after the delivery of the baby almost all $100 \%$ (50) of care provided by TM was according to WHO \& ICM competencies in private hospital and $92 \%$ (46) of care in government hospital was according to WHO \& ICM competencies but $8 \%$ (4) of care provided was not practiced accordingly. In third stage of labour, 100\% (50) of care was according to WHO \& ICM competencies in private hospital whereas $94 \%$ (47) was of according to WHO \& ICM competencies and $6 \%$ (3) was not according to it in government hospital.

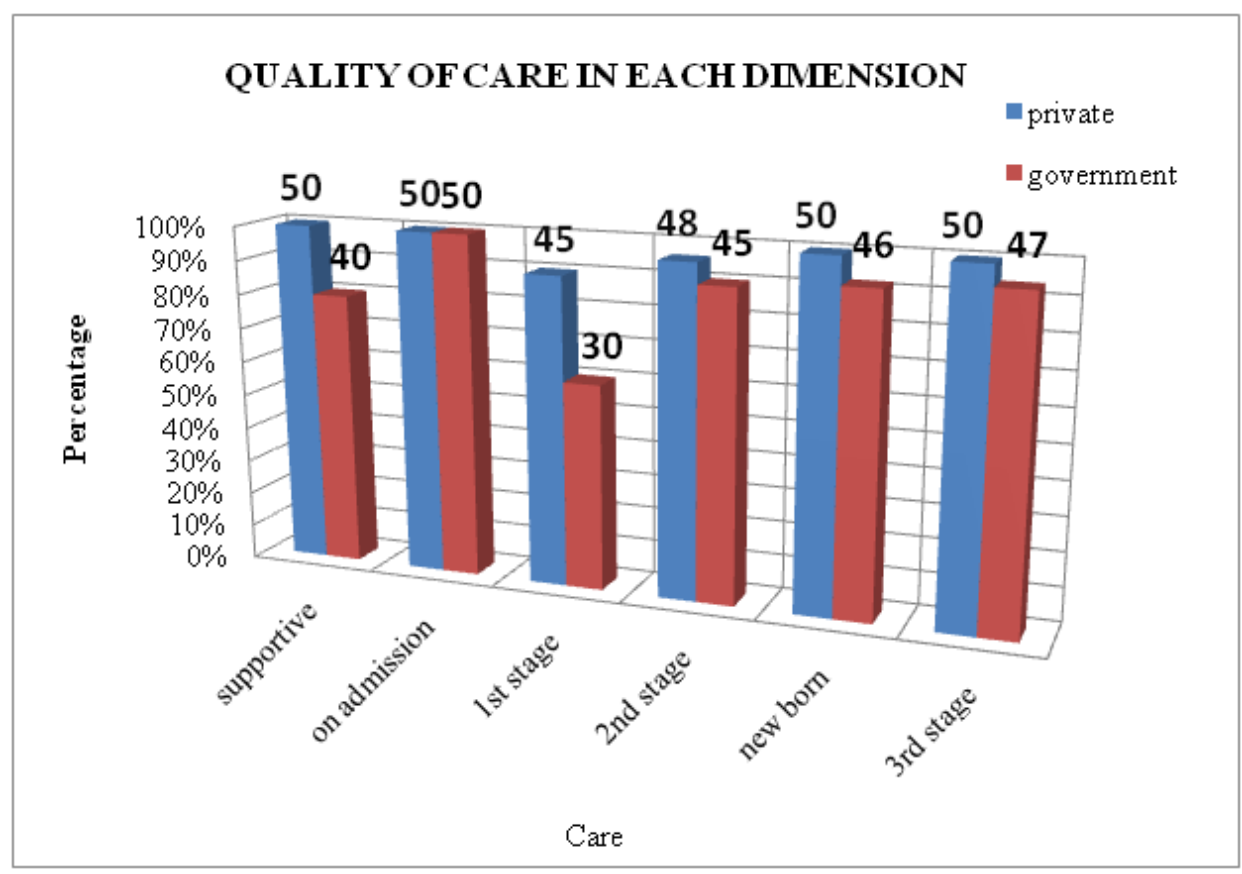

Fig: clustered column graph showing percentage distribution of quality of care in each dimensions.

\section{CONCLUSION}

After the detailed analysis, this study leads to the following conclusions: -

The results revealed that there is a vast difference between the practices of private and government hospitals; out of 58 selected competencies of WHO \& ICM only 10 of the competencies were better in government hospital as compared to private hospital. It is found that years of experience or the age maturity of practitioners cannot provide a better care unless the practices are updated and adequate supervision is ensured, as the entire TM in government hospitals have more experience as compared to private hospital but the quality of care of private hospital is much better. This is because private hospitals have strict supervision and they have certain quality indicators which are to be followed by each TM. Through this study, it is observed that old practices which have formed a habit are difficult to change, so there should be skill enhancement trainings provided to TM working in the labour unit so as to change their old perceptions and to make midwives competent enough to provide care skilfully and to protect the rights of women in labour.

\section{RECOMMENDATION}

- A similar study can be replicated on a larger scale.

- Regular educational programmes in service should be conducted

- There should be strict supervision of TM.

- Skill enhancement should be given.

- $\quad$ Proper Quality assurance is to be established so as to encourage the TM to provide quality care. 


\section{ARTICLES}

\section{REFERENCES}

1. Dutta, D.C (2004). Text Book of Obstetrics including perinatology and contraception. (6th edition), New Central Book Agency, p.411-413.

2. Kothari, C.R (2006). Research Methodology, 2nd Ed, New Delhi: New Age International Limited Publishers.

3. Bahri, N., Ali Vafaee, N., Ebrahimipour, H., Askari, F., Bashir, K., (2014) Quality of Labor Support during Labor. Patient Saf Qual Improv, 2(1), 58-64.

4. Begley CM (2010 July), Active versus expectant management for women in the third stage of labour; Cochrane. Retrieved from https://www.researchgate.net/publication/45102941

5. Bloom, SL (2006 January), A randomized trial of coached versus uncoached maternal pushing during the second stage of labor. Am J Obstet Gynecol. 194(1):10-3.

6. Bowers BB (2002 November), Mothers' experiences of labor support: exploration of qualitative research; pub med. Journal of Obstetric Gynecol Neonatal Nurs. 31(6):742-52.

7. Brown, KM. (2000) Management guidelines for women's health nurse practitioners. American Journal of Primary Health Care, 30(4), 12-25. 